\title{
A New Method for Determining the Nanocrystallite Size Distribution in Systems Where Chemical Reaction between Solid and a Gas Phase Occurs
}

\author{
Rafał Pelka and Walerian Arabczyk \\ West Pomeranian University of Technology, Szczecin, Institute of Chemical and Environment Engineering, Pułaskiego 10, \\ 70-322 Szczecin, Poland \\ Correspondence should be addressed to Rafał Pelka; rpelka@zut.edu.pl
}

Received 5 February 2013; Accepted 9 March 2013

Academic Editor: Diego Gomez-Garcia

Copyright (C) 2013 R. Pelka and W. Arabczyk. This is an open access article distributed under the Creative Commons Attribution License, which permits unrestricted use, distribution, and reproduction in any medium, provided the original work is properly cited.

\begin{abstract}
The proposed method, based on measuring the chemical reaction rate in solid phase, is, therefore, limited to such systems where reaction between nanocrystalline materials and a gas phase occurs. Additionally, assumptions of the model of reaction between nanocrystalline materials and a gas phase, where the surface chemical reaction rate is the rate limiting step, are used. As an example of such a reaction, nitriding (with ammonia) of the prereduced industrial iron catalysts for ammonia synthesis of different average crystallite sizes was used. To measure the reaction rate, the differential reactor equipped with systems for thermogravimetric measurements and analysis of the chemical composition of the gas phase was used. The crystallites mass and size distributions for the analyzed samples of catalyst were determined.
\end{abstract}

\section{Introduction}

Particle or grain size distribution is an important parameter in many processes and its precise measurement is required to accurately control the course of these processes. Measurement of the particle/grain size distribution is important, for example, in such industries as, chemical (e.g., catalysts), cosmetic, pharmaceutical, electronic (semiconductor manufacturing), ceramic, and photographic. Thus, the grain size distribution (GSD) determination became the fundamental measurement when dealing with the nanomaterials, because properties of these materials depend on diameter of nanoparticles [1-4]. In materials having particle sizes below $100 \mathrm{~nm}$, a strong dependence of physical and chemical properties on the particle sizes is observed [5,6]. Determining of the average particle size as a parameter characterizing the material is insufficient and that information should be supplemented by grain size distribution.

Conventional measurement techniques and methods for GSD determining elaborated for particles with sizes greater than $0.1 \mu \mathrm{m}$ are unreliable for materials with smaller grain sizes. Widely used classical method for determining the size of nanocrystallites based on the diffraction measurements using Scherrer's equation enables one to determine the average crystallite size. In this method, the information about the FWHM value (peak width at half height-full width at half maximum) of the diffraction peak is used. Additionally, to get the information about the distribution of crystallite sizes, the diffraction line profile is to be analyzed [7-11]. The method for determining the size distribution of crystallites, which is intended to measure the width of the diffraction peak at two levels: in the fifth and four fifths of the peak height instead of the previously applied FWHM was proposed [7]. This method also enables one to obtain information on the size distribution of grains in different crystallographic directions. Crystallite size distribution can be measured also by X-ray diffraction method of WarrenAverbach or the method proposed in Vogel's work [12] (based on two simple analytical functions containing a single structural parameter, derived by consideration of boundary conditions for the so-called "column length distribution" of crystallites; spherically shaped crystallites are assumed), by 
electron microscopy (SEM, TEM), by methods using results of gas adsorption/desorption measurements, for example, by BET method (such kind of method provides information related to the crystallite surface area), by optical methods used to count single particles passing through a laser beam, or by the chemical method already described [13]. The last method uses the results of measurements of the average crystallite size (of substrate or product) corresponding to given conversion degrees. From the dependence of the average size of crystallites of substrate or product on the conversion degree, it is possible to determine the crystallite size distribution. Methods using results of XRD measurements are related to the crystallite volume. All methods based on XRD measurements are limited to crystalline substances. There may be differences between the results obtained by the "volumetric" and "surface" methods. This may be due to the fact that, for example, agglomerates of small crystallites are in the "surface" method treated as one large crystallite.

Classical methods for distribution determining mostly assume 1-modal distributions of particles. This is true only for some specific cases. Many substances are characterized by 2- or 3-modal distributions. An example of such a substance may be iron catalyst for ammonia synthesis. It is composed of two different phases-magnetite and wustite. Commonly known methods are not proper for such materials. The proposed method enables one to determine the real size distribution of nanoparticles.

During the analysis of the reactions between nanocrystalline iron and a gas phase, particularly ammonia [14-17], oxygen $[18,19]$, and hydrocarbons $[20,21]$, the previously unknown phenomenon was observed. Namely, the average crystallite size of the substrate increases with the progress of the reaction. In order to explain this phenomenon, a model of reaction of nanocrystalline materials with the gas phase was proposed, in which the rate of the process is limited by the rate of adsorption, $r_{a}[15,22]$.

The rate of the chemical process between solid and gas phase in the kinetic region may be limited by rate of adsorption or chemical reaction. Langmuir-Hinshelwood assume [23] that two molecules adsorb and then undergo a reaction. The reaction rate is

$$
r=k \theta_{A} \theta_{B} C_{S}^{2}
$$

where $k$ is the reaction rate constant; $\theta$ is the surface coverage; $C_{S}$ is the total number of sites; subscripts $A$ and $B$ refer to substrate $A$ and $B$.

Eley-Rideal stated [23] that only one of the molecules adsorbs $(A)$ and the other one $(B)$ reacts with it directly from the gas phase, without adsorbing. Then, the reaction rate is

$$
r=k C_{S} \theta_{A} C_{B}
$$

where $C_{B}$ is the concentration of substance $B$ in the gas phase.

The proposed model assumes adsorption as a rate limiting step. The rate of adsorption for a single crystallite can be described by the equation in [24]:

$$
r_{a}=p k_{a} S(1-\theta)^{n}
$$

where $p$ is the gas reactant pressure; $k_{a}$ is the adsorption rate constant; $S$ is the surface area; $\theta$ is the surface coverage degree; $n$ is the number of active sites occupied by one adsorbed particle.

A part of products of the surface reaction is dissolved in a crystallite volume, and the rest remains on a solid surface. If the rate of adsorption limits the rate of the process, there is no concentration gradient in nanocrystallite volume. After exceeding the critical concentration of the substance dissolved in a volume of crystallite, $X_{b(\mathrm{CR})}$, crystallites undergo the phase transition (recrystallization) as a whole. New crystallographic structure is not fully saturated and thus absorbs gas reactant easily. Between the substance on the surface and in volume, the state of thermodynamic equilibrium holds, which can be described by LangmuirMcLean equation in [24, 25]:

$$
\frac{\theta}{1-\theta}=\frac{X_{b}}{1-X_{b}} e^{-\Delta G\left(X_{b}\right) / R T},
$$

where $X_{b}$ is the crystallite bulk concentration; $\Delta G\left(X_{b}\right)$ is the free enthalpy of segregation; $R$ is the gas constant; $T$ is the temperature.

Free enthalpy of segregation may depend on concentration $X_{b}$ when $X_{b}$ is relatively high, as Fowler and Guggenheim propose [26]:

$$
\Delta G\left(X_{b}\right)=\Delta G_{0}+a X_{b},
$$

where $\Delta G_{0}$ is the standard free enthalpy of segregation; $a$ is the proportionality coefficient.

Time after which the critical bulk concentration is achieved depends on the crystallite surface area, $S$, on which chemical reaction takes place and on its volume, $V$, in which an increase in concentration occurs until the $X_{b(\mathrm{CR})}$ is achieved. At the beginning, small crystallites react, then greater, and finally the greatest. As a result, iron nanocrystallites underwent phase transition in the order according to their size-from the smallest to the largest. Change in the crystallographic lattice causes a sharp change in values of the free enthalpy of segregation function, which at this point is discontinuous. At the time of the occurrence of phase transition, also the rapid change in the surface coverage degree, $\theta$, between substrate and product phase appears $\left(\theta_{p} \ll \theta_{s}\right)$.

Assumptions of the model were expressed mathematically, and model calculations concerning the processes occurring in the course of the reaction in the system of nanocrystalline solid-gas were carried out in order to verify the model assumptions by comparing the obtained model results with experimental data [22]. As a result of modeling, values of some process parameters were estimated that are impossible or difficult to determine on the basis of experimental data. In this way, the values of such parameters as the parameters of thermodynamic functions, the degree of surface coverage of solid state with a gas, and changes of concentrations in crystallites were set, and the influence of parameters of size distribution of crystallites on the rate of the process was estimated [22]. 
By adopting the assumptions of the proposed model, a method for determining the size distribution of crystallites was already developed [13]. The method makes use of the results of thermogravimetric measurements (TG) as well as of X-ray diffraction (XRD).

The aim of the present work is to present a new methodbased on the model of reaction of nanocrystalline materials with the gas phase, in which the rate of adsorption is the rate limiting step-for determining the size distribution of iron nanocrystallites in the iron catalyst on the basis of measurements of the rate of chemical reactions in the solid phase, for example, by TG method, and measurements of concentrations of the reactants present in the gas phase.

\section{Experimental}

The research was carried out using the prereduced industrial iron catalyst for ammonia synthesis. The composition of the catalyst was determined by inductively coupled plasma method (ICP-OES, spectrometer Perkin Elmer, type Optima 5300DV) (wt.\%): $3.3 \mathrm{Al}_{2} \mathrm{O}_{3}, 2.8 \mathrm{CaO}, 0.65 \mathrm{~K}_{2} \mathrm{O}$. Oxygen in the form of iron oxides was $6.5 \mathrm{wt} . \%$. Fraction of catalyst particles from the range $1.0-1.2 \mathrm{~mm}$ was used. A catalyst sample of ca. $1 \mathrm{~g}$ was placed in a form of a single layer of grains in a platinum basket hanging on the arm of the thermobalance.

Kinetics of the nitriding process of the catalyst samples were studied by means of differential tubular reactor, which allows simultaneous thermogravimetric measurement of nitrogen content in the solid samples and catharometric measurement of concentration of hydrogen in the gas mixture. Detailed description of the analytical equipment is given in work [14].

Nitriding process was preceded by the reduction process of the passive layer of a catalyst and heating under a hydrogen atmosphere at different temperatures with a load of pure hydrogen (99.999\%) $150 \mathrm{~cm}^{3} \mathrm{~min}^{-1} \mathrm{~g}^{-1}$ and at atmospheric pressure. Catalyst samples were heated at a temperature of $500^{\circ} \mathrm{C}(A)$ or $700^{\circ} \mathrm{C}(B)$. As a result of heating, samples with different average crystallite sizes were obtained. After the reduction, the samples are porous, and the void ratio is 0.5 .

Nitriding was performed under the atmosphere of ammonia-hydrogen mixtures of variable values of the nitriding potential, $P=p_{\mathrm{NH}_{3}} / p_{\mathrm{H}_{2}}^{3 / 2}$, with a total load of $200 \mathrm{~cm}^{3} \mathrm{~min}^{-1} \mathrm{~g}^{-1}$, at $475^{\circ} \mathrm{C}$ and under atmospheric pressure. Concentration of hydrogen in the reaction volume, which resulted from the ammonia load and the course of the ammonia decomposition and nitriding reaction, was determined. The process was carried out under unsteady state. Taking into account the mass balance of the reactor with ideal mixing, concentrations of ammonia and nitrogen in the gas mixture were calculated as described in work [16].

On the basis of the results of the X-ray diffraction measurements (X-ray diffractometer Philips X'Pert PRO, $\mathrm{CuK} \alpha$, Almelo, The Netherlands), the values of the average nanocrystallites size in samples $A$ and $B$, equal to $20 \mathrm{~nm}$ and $40 \mathrm{~nm}$, respectively, were determined by Scherrer's method.
To determine the distribution of pores sizes and the specific surface area, the BET method was used (Quadrasorb SI, Quantachrome).

\section{Results and Discussion}

Thermogravimetric curve $(m=f(t))$ for the nitriding process of sample $A$ as well as the corresponding changes in the rate of the nitriding reaction $\left(r_{\text {nit }}=f(t)\right)$ are shown in Figure 1(a). Stoichiometric composition of $\gamma^{\prime}-\mathrm{Fe}_{4} \mathrm{~N}$ is marked on the plot.

Changes in hydrogen concentration, $X_{\mathrm{H}_{2}}$, during the nitriding process of sample $A$ are shown in Figure 1(b). After approximately $500 \mathrm{~s}$, steady state is achieved-nitriding reaction rate is zero. Then, only a reaction of catalytic decomposition of ammonia takes place. Hydrogen concentration in this stage of the process informs about the reaction rate of catalytic decomposition of ammonia on the formed nitride phase.

Stationary state during nitriding process depends on temperature, nitriding potential, and ammonia load. Thus, process conditions were chosen so that only $\gamma^{\prime}$ phase was obtained in the stationary state, and the following analysis is limited only to the values concerning the rate of creating of $\gamma^{\prime}-\mathrm{Fe}_{4} \mathrm{~N}$ phase from $\alpha$-iron. The conversion degree, $\alpha$, is defined as the ratio of the mass of nitrogen attached to iron in a given moment of chemical reaction to the mass of nitrogen which is in the $\gamma^{\prime}-\mathrm{Fe}_{4} \mathrm{~N}$ nitride. After taking into account that the nitriding reaction rate depends not only on nitriding potential and temperature, but also on the iron conversion degree, the nitriding reaction rate can be described by the following equation in [14]:

$$
r_{\text {nit }}=k\left(P-P_{0}\right) f(\alpha),
$$

where $k$ is the nitriding reaction rate constant; $P_{0}$ is the minimum nitriding potential required to start the nitriding reaction, namely, concentration $X_{b}$ reaches the value $X_{b(\mathrm{CR})}$ for the smallest crystallite.

Taking into account results of hydrogen concentration measurements and mass balance of the reactor with ideal mixing, concentrations of ammonia and nitrogen in the gas mixture were calculated for every moment of the chemical process. Then, the dependence of natural logarithm of potential $P$ on conversion degree was determined (Figure 2 ).

From Figure 2, it can be concluded that at the beginning of the nitriding process there is a small increase in mass of solid sample $(\alpha=0.03 \div 0,06)$ in a wide range of nitriding potential, $\ln P=-8.4 \div-6.2$. In this range, a solution of nitrogen in $\alpha$-iron was formed. Then, similar increase in nitriding potential $(\ln P=-6.2 \div-4)$ results in much greater increase in mass $(\alpha=0.06 \div 1)$. This corresponds to the course of nitriding reaction and saturation of iron nitrides. The boundary value, $\ln P=-6.2=\ln P_{0}$, indicates the beginning of nitriding reaction.

Value of minimal nitriding potential, $P_{0}$, determined on the basis of Figure 2 was used to calculate the value of expression $r_{\text {nit }} /\left(P-P_{0}\right)$. In Figure 3 , the dependence of $r_{\text {nit }} /\left(P-P_{0}\right)$ is presented as a function of conversion degree, $\alpha$. 


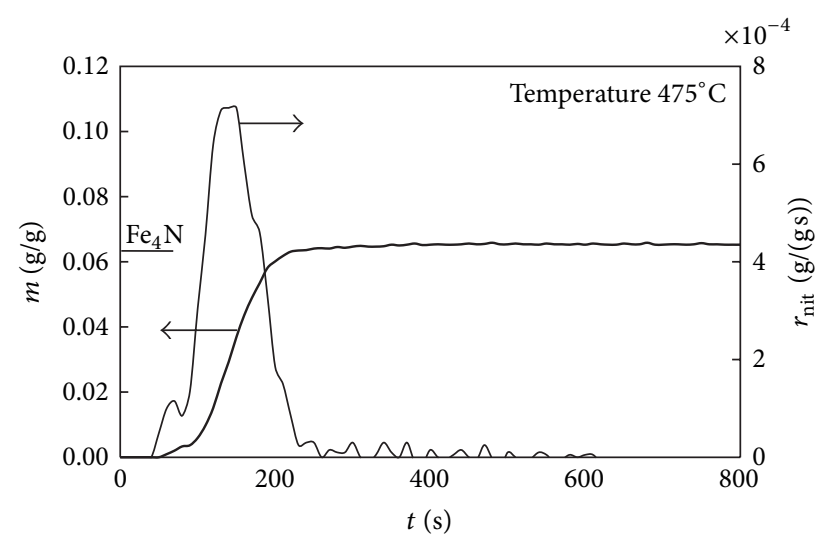

(a)

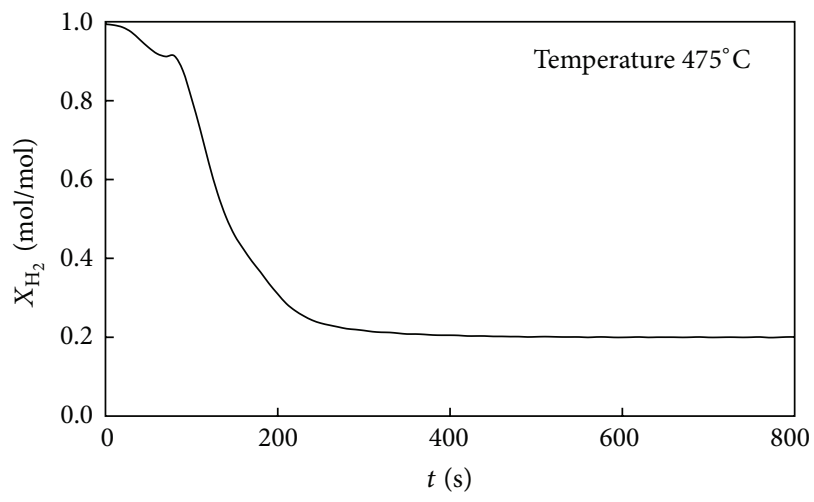

(b)

Figure 1: (a) Nitriding degree, $m$, versus time, $t$ (TG curve), and nitriding reaction rate, $r_{\text {nit }}$, versus time (DTG curve). (b) Hydrogen concentration changes in the reactor during the nitriding process; sample $A$.

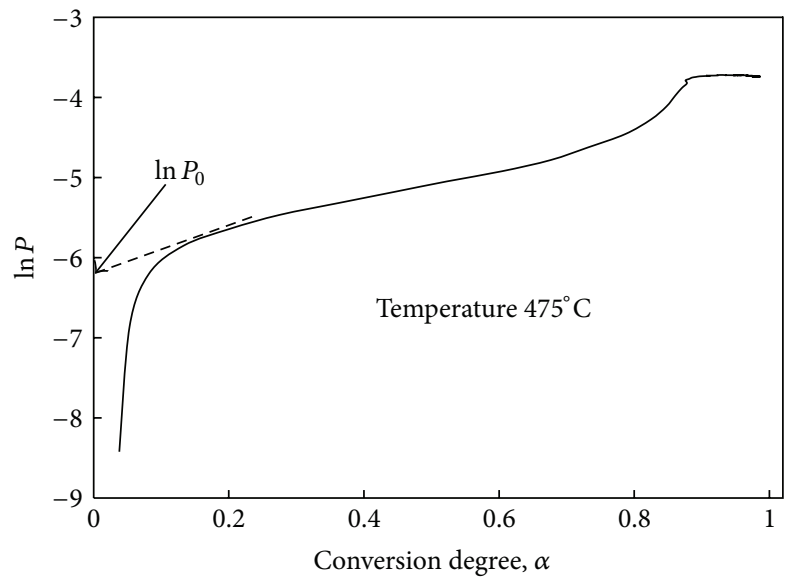

FIGURE 2: Natural logarithm of nitriding potential, $\ln P$, as a function of conversion degree, $\alpha$ (sample $A$ ).

Assuming that the time needed to reach a critical concentration in the crystallite volume is much longer than the time of occurrence of the phase transition and after setting up values of such parameters as adsorption rate constant $\left(k_{a}=30\right)$, free enthalpy of segregation (three phases: $\Delta G_{01}=$ $-90 \mathrm{~kJ} / \mathrm{mol}, a_{\mathrm{I}}=0, \Delta G_{0 I \mathrm{II}}=20 \mathrm{~kJ} / \mathrm{mol}, a_{\mathrm{II}}=-100$, $\left.\Delta G_{0 I I I}=120 \mathrm{~kJ} / \mathrm{mol}, a_{\mathrm{III}}=-610\right)$, critical concentration in the volume $\left(X_{b(\mathrm{CR}) \mathrm{I}}=0.0012 \mathrm{~mol} / \mathrm{mol}, X_{b(\mathrm{CR}) \mathrm{II}}=\right.$ $\left.0.2 \mathrm{~mol} / \mathrm{mol}, X_{b(\mathrm{CR}) \mathrm{III}}=0.33 \mathrm{~mol} / \mathrm{mol}\right)$, and temperature $(723 \mathrm{~K})$, the time required for the occurrence of the phase transition of $\alpha$ phase to $\gamma^{\prime}, t_{n}=f(S, V)$ (marked with " $X$ " in Figure 4), was determined for a particular crystallite. The time $t_{1}$, after which the smallest crystallite reaches the critical volume concentration, was applied as the reference time, and to this unit the times $t_{n}$ were related. Times $t_{n}$ are needed by greater $n$th crystallites to reach the critical concentration in their volume, which is necessary for the phase transition. In this way, standardized times $t_{n}^{\prime}=t_{n} / t_{1}$ were determined.

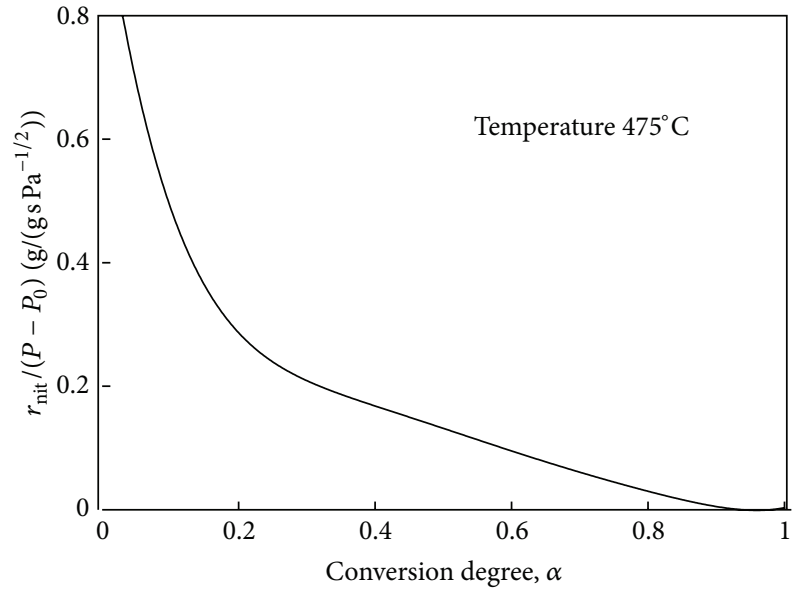

FIGURE 3: The dependence of $r_{\text {nit }} /\left(P-P_{0}\right)$ as a function of conversion degree, $\alpha$ (sample $A$ ).

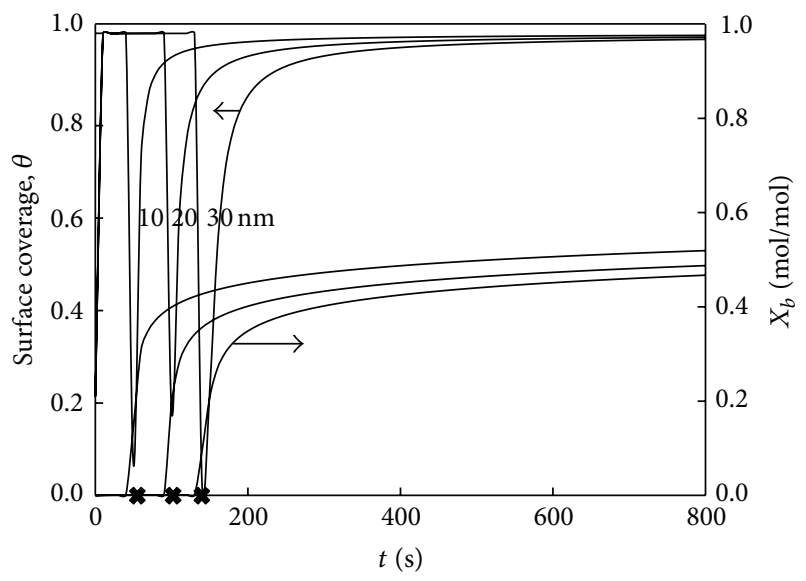

FIGURE 4: Bulk concentration, $X_{b}$, and the surface coverage degree, $\theta$, dependences on time for three exemplary single crystallites of different diameters $(10,20$, and $30 \mathrm{~nm})$. 


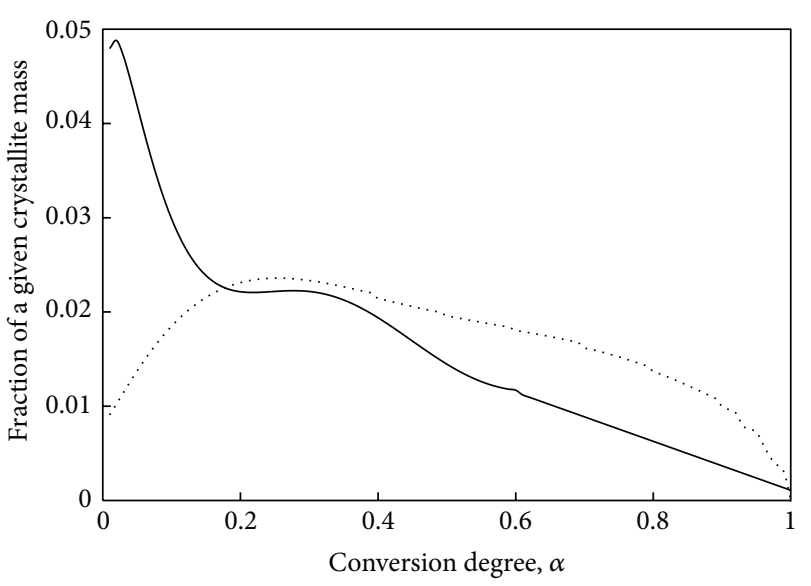

- A

FIGURE 5: The probabilities of the particular mass of crystallites in the samples $A$ and $B$ as functions of conversion degree.

As a result of the performed studies, a connection between mass distribution function of crystallites and the rate of nitriding reaction was described by the following expression in [14]:

$$
\begin{aligned}
r_{\text {nit }} & =\frac{\alpha k(T) f(P)}{t_{n}^{\prime}}=\frac{\operatorname{Qmk}(T) f(P)}{t_{n}^{\prime} \sum Q m} \\
& =f(\mathrm{GMD}) \frac{k(T) f(P)}{t_{n}^{\prime}},
\end{aligned}
$$

where $\alpha$ is the conversion degree of iron; $k$ is the reaction rate constant; $Q$ is the probability; $m$ is the nitriding degree; GMD is the grain mass distribution function; $t_{n}^{\prime}$ is the time after which the $n$th crystallites reach the critical bulk concentration.

The shapes of mass distribution function of crystallites from samples $A$ and $B$ (Figure 5) were determined by using (7). These values were determined with the regard for the smallest iron crystallite in the analyzed sample.

In Figure 6, the obtained crystallite size distributions for samples $A$ and $B$ are presented. The range of crystallites diameters for every sample was chosen so that the mean diameter, resulting from GSD, was the same like calculated using Scherrer's equation.

Changes of mass and size distributions resulting from a recrystallization process were determined. In course of the recrystallization at higher temperature $\left(700^{\circ} \mathrm{C}\right)$, the amount of smaller crystallites decreases, but there is more larger crystallites in the sample, in comparison to sample reduced at $500^{\circ} \mathrm{C}$.

The results of XRD measurements were also used to determine the distribution of nanocrystallites sizes by means of Pielaszek's method described in [7].

The porosity of the analyzed material is 0.5 . This implies that the pore size distribution corresponds with the iron nanocrystallites size distribution in the solid samples. The obtained size distribution for sample $A$ was compared with

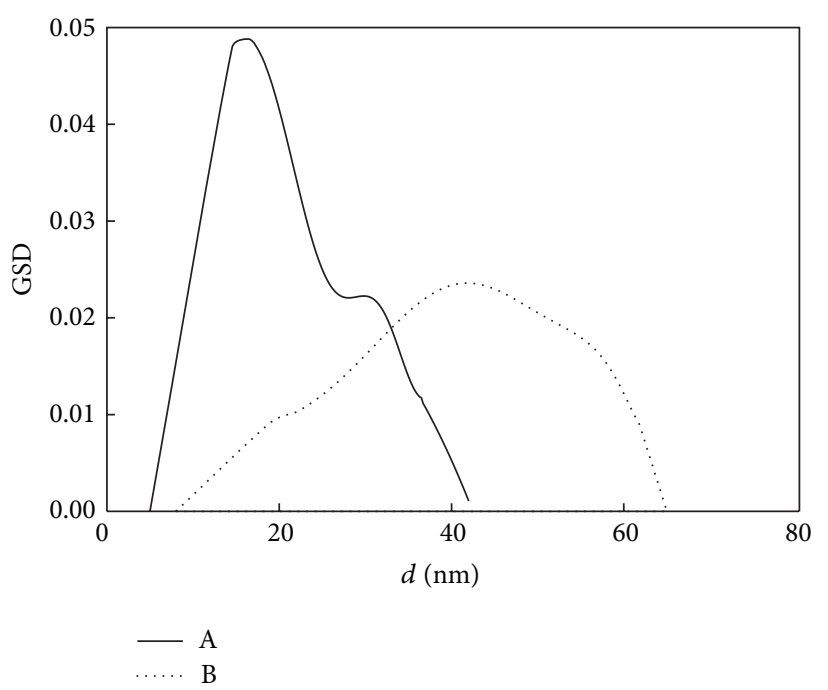

FIgURE 6: Crystallite size distributions for samples $A$ and $B$.

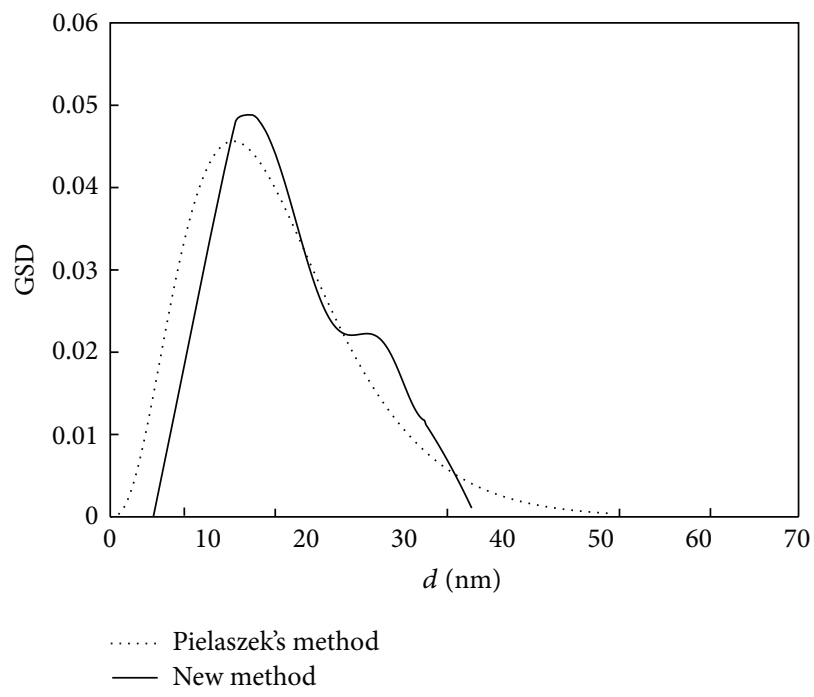

FIGURE 7: Comparison of GSDs obtained by means of Pielaszek's, BET, and chemical (new) method.

results obtained by means of XRD method (after Pielaszek) and BET method (Figure 7).

As it can be seen, new chemical method shows similar results like classical methods. This means that the obtained GSD can be verified by other conventional methods. However, a new method makes it possible to determine the GSD more precisely. The new method has no, for example, mathematical, simplification. Another advantage of the proposed method is the simplicity of the procedure. To determine the GSD, only TG measurements and gas phase chemical composition analysis have to be performed.

\section{Conclusions}

The nitriding process of ammonia synthesis iron catalyst was studied. A surface reaction was assumed to be the rate 
limiting step. Results of the reaction rates measurements were interpreted by means of the reaction model, in which the chemical reaction rate is the rate limiting step.

The nitriding degree of the solid samples depended on the nitriding potential of a gas phase. At the stationary state, a constant potential was observed.

A connection between mass distribution function of crystallites and the rate of nitriding reaction was used to determine the shapes of the crystallites mass/size distributions. It was possible to determine the changes of mass distributions resulting from a recrystallization process. It was observed that in course of the recrystallization at higher temperature $\left(700^{\circ} \mathrm{C}\right)$, the amount of smaller crystallites decreases, but there is more larger crystallites in the sample, in comparison to sample reduced at $500^{\circ} \mathrm{C}$.

\section{Acknowledgment}

This scientific work was financed by the budgetary resources for science in 2010-2013 as a research project-Project no. NN 209413039.

\section{References}

[1] J. Karch, R. Birringer, and H. Gleiter, "Ceramics ductile at low temperature," Nature, vol. 330, no. 6148, pp. 556-558, 1987.

[2] M. Ruhle, H. Dosch, E. J. Mittemejer, and M. H. van de Voorde, Eds., European White Book on Fundamental Research in Materials Science, Max-Planck Institute for Metals Research, Stuttgart, Germany, 2001.

[3] W. Lojkowski and H. J. Fecht, "Structure of intercrystalline interfaces," Progress in Materials Science, vol. 45, no. 5, pp. 339$568,2000$.

[4] M. Poliakoff and P. King, "Phenomenal fluids," Nature, vol. 412, no. 6843 , p. $125,2001$.

[5] H. Gleiter, "Nanostructured materials: basic concepts and microstructure," Acta Materialia, vol. 48, no. 1, pp. 1-29, 2000.

[6] I. E. Beck, V. I. Bukhtiyarov, I. Y. Pakharukov, V. I. Zaikovsky, V. V. Kriventsov, and V. N. Parmon, "Platinum nanoparticles on $\mathrm{Al}_{2} \mathrm{O}_{3}$ : correlation between the particle size and activity in total methane oxidation," Journal of Catalysis, vol. 268, no. 1, pp. 6067, 2009.

[7] R. Pielaszek, "FW 1/5/4/5 M method for determination of the grain size distribution from powder diffraction line profile," Journal of Alloys and Compounds, vol. 382, no. 1-2, pp. 128-132, 2004.

[8] P. Ganesan, H. K. Kuo, A. Saavedra, and R. J. De Angelis, "Particle size distribution function of supported metal catalysts by X-ray diffraction," Journal of Catalysis, vol. 52, no. 2, pp. 310320,1978 .

[9] T. Ungár, J. Gubicza, G. Ribárik, and A. Borbély, "Crystallite size distribution and dislocation structure determined by diffraction profile analysis: principles and practical application to cubic and hexagonal crystals," Journal of Applied Crystallography, vol. 34, pp. 298-310, 2001.

[10] T. Ungár, "Characterization of nanocrystalline materials by Xray line profile analysis," Journal of Materials Science, vol. 42, no. 5, pp. 1584-1593, 2007.
[11] T. Ida, T. Goto, and H. Hibino, "Particle statistics in synchrotron powder diffractometry," Zeitschrift für Kristallographie Proceedings, vol. 1, pp. 69-74, 2011.

[12] W. Vogel, "Size distributions of supported metal catalysts: an analytical X-ray line profile fitting routine," Journal of Catalysis, vol. 121, no. 2, pp. 356-363, 1990.

[13] W. Arabczyk and R. Wróbel, "Utilisation of XRD for the determination of the size distribution of nanocrystalline iron materials," Diffusion and Defect Data B, vol. 94, pp. 235-238, 2003.

[14] R. Pelka and W. Arabczyk, "Studies of the kinetics of reaction between iron catalysts and ammonia-nitriding of nanocrystalline iron with parallel catalytic ammonia decomposition," Topics in Catalysis, vol. 52, no. 11, pp. 1506-1516, 2009.

[15] W. Arabczyk and R. Wróbel, "Study of the kinetics of nitriding of nanocrystalline iron using TG and XRD methods," Diffusion and Defect Data B, vol. 94, pp. 185-188, 2003.

[16] W. Arabczyk and R. Pelka, "Studies of the kinetics of two parallel reactions: ammonia decomposition and nitriding of iron catalyst," Journal of Physical Chemistry A, vol. 113, no. 2, pp. 411-416, 2009.

[17] K. Kiełbasa, R. Pelka, and W. Arabczyk, "Studies of the kinetics of ammonia decomposition on promoted nanocrystalline iron using gas phases of different nitriding degree," Journal of Physical Chemistry A, vol. 114, no. 13, pp. 4531-4534, 2010.

[18] R. Pelka, A. Pattek-Janczyk, and W. Arabczyk, "Studies of the oxidation of nanocrystalline iron with oxygen by means of TG, MS, and XRD methods," Journal of Physical Chemistry C, vol. 112, no. 36, pp. 13992-13996, 2008.

[19] K. Lubkowski, W. Arabczyk, B. Grzmil, B. Michalkiewicz, and A. Pattek-Janczyk, "Passivation and oxidation of an ammonia iron catalyst," Applied Catalysis A, vol. 329, pp. 137-147, 2007.

[20] W. Arabczyk, W. Konicki, U. Narkiewicz, I. Jasińska, and K. Kałucki, "Kinetics of the iron carbide formation in the reaction of methane with nanocrystalline iron catalyst," Applied Catalysis A, vol. 266, no. 2, pp. 135-145, 2004.

[21] W. Arabczyk, W. Konicki, and U. Narkiewicz, "The size distribution of iron nanoparticles produced by the carburisation process," Diffusion and Defect Data B, vol. 94, pp. 177-180, 2003.

[22] R. Wróbel and W. Arabczyk, "Solid-gas reaction with adsorption as the rate limiting step," Journal of Physical Chemistry A, vol. 110, no. 29, pp. 9219-9224, 2006.

[23] G. Ertl, Reactions at Solid Surfaces, Wiley, New Jersey, NJ, USA, 2009.

[24] I. Langmuir, "The adsorption of gases on plane surfaces of glass, mica and platinum," The Journal of the American Chemical Society, vol. 40, no. 9, pp. 1361-1403, 1918.

[25] J. Benard, Ed., Adsorption on Metal Surfaces: An Integrated Approach (Studies in Surface Science And Catalysis Series, No. 13), Elsevier, New York, NY, USA, 1983.

[26] R. H. Fowler and E. A. Guggenheim, Statistical Thermodynamics, Cambridge Univeristy Press, Cambridge, UK, 1939. 

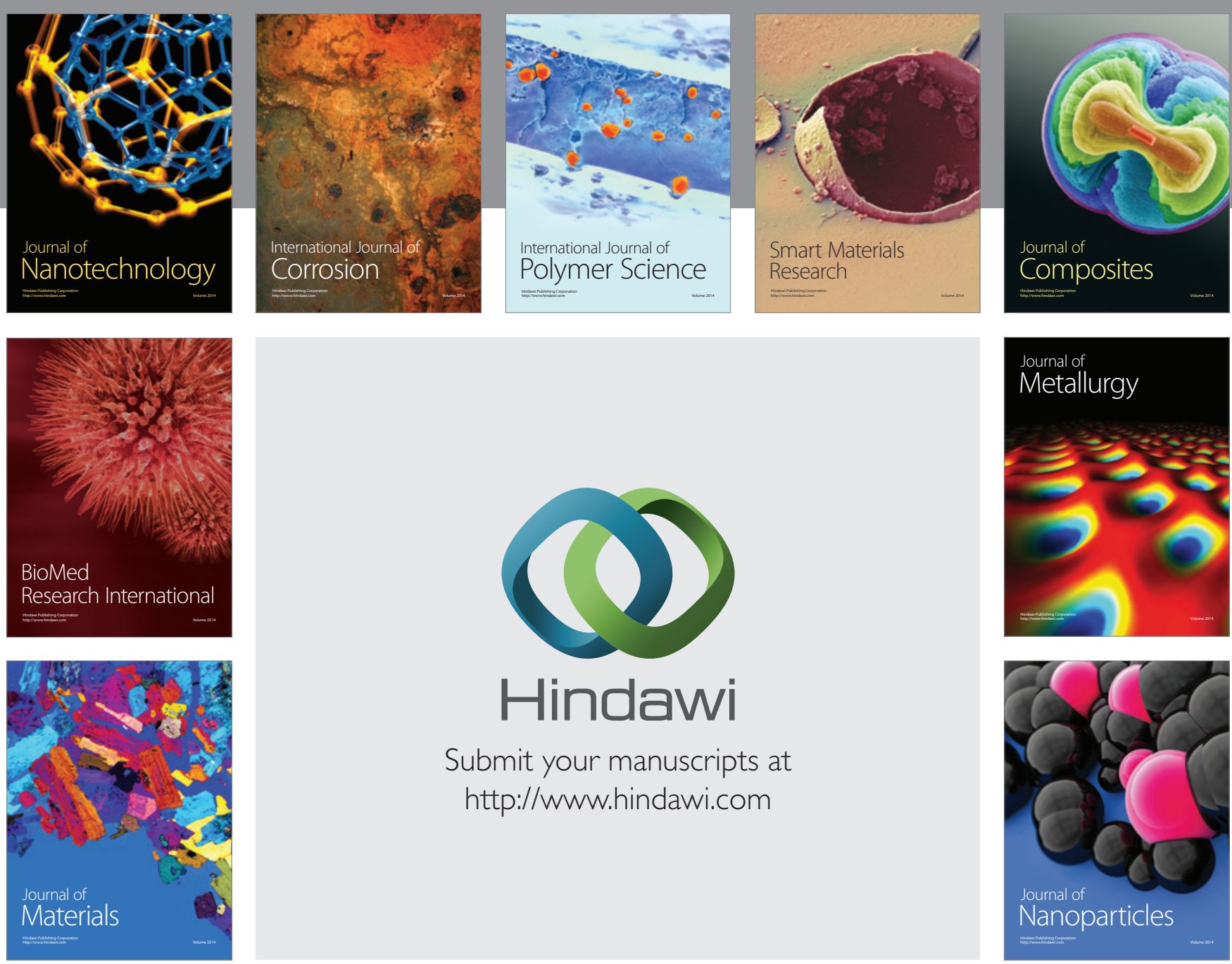

Submit your manuscripts at http://www.hindawi.com
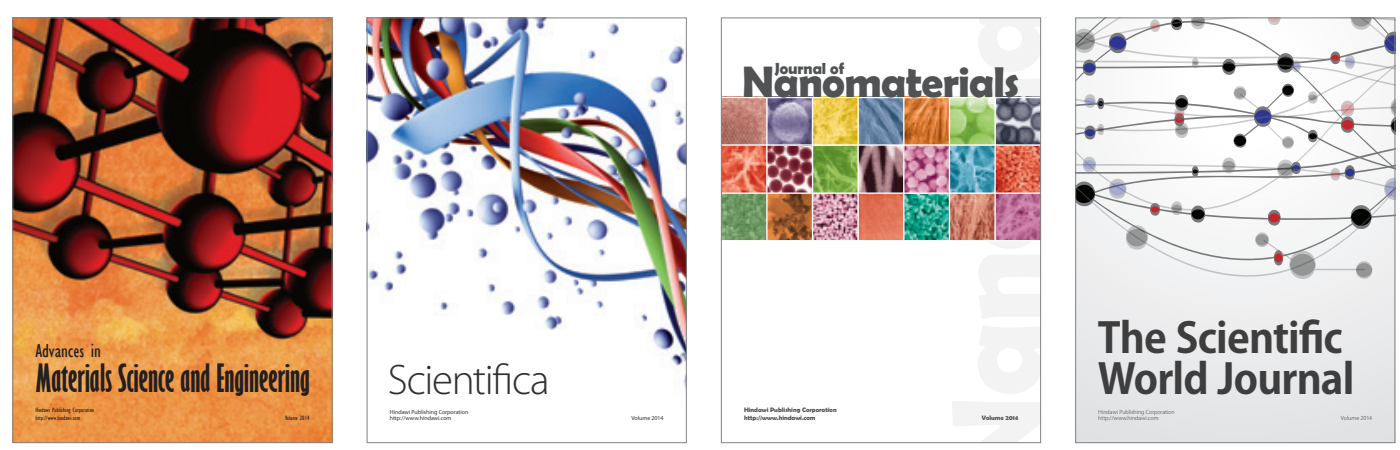

\section{The Scientific World Journal}
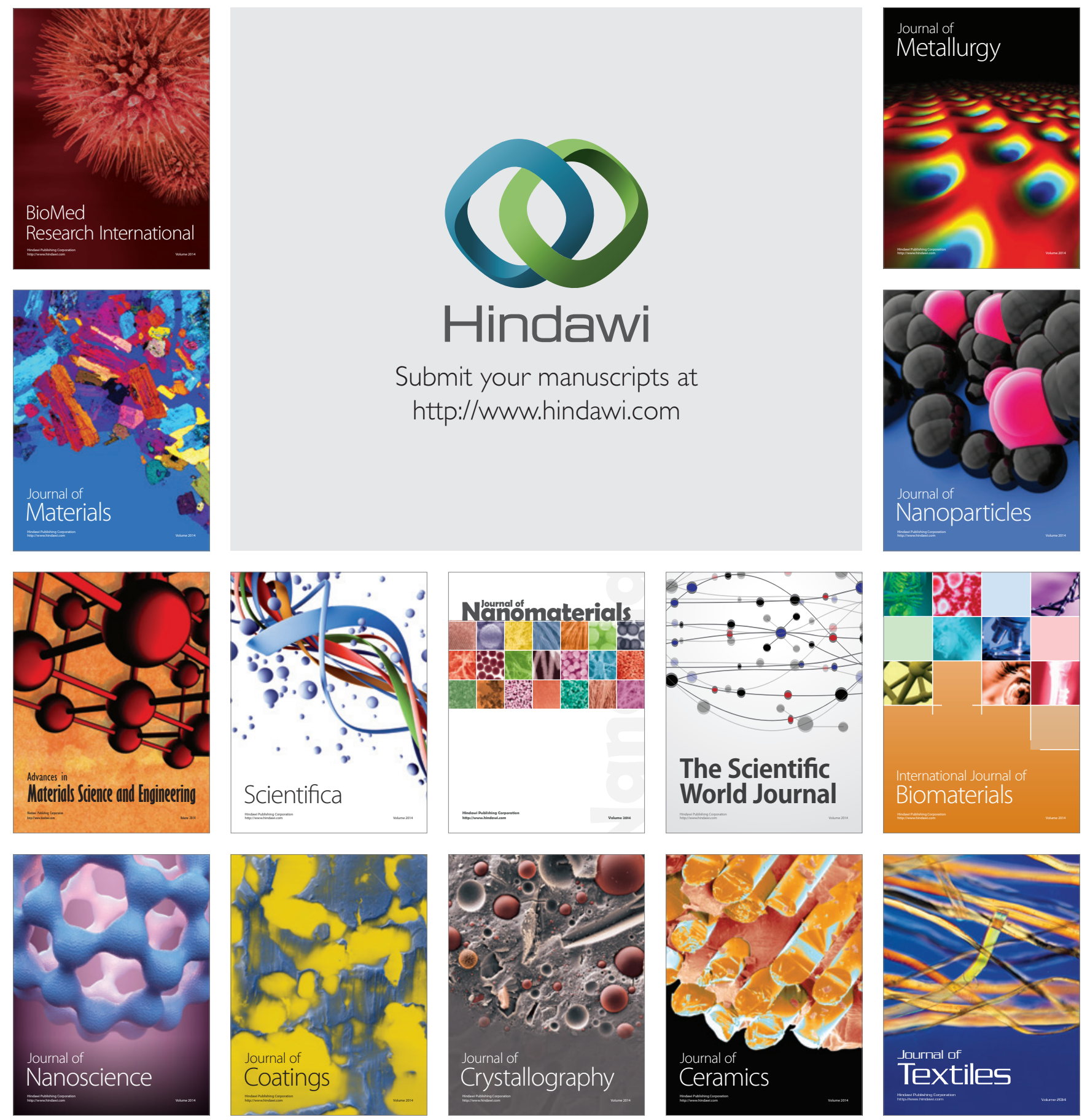